Check for updates

Cite this: Phys. Chem. Chem. Phys., 2017, 19, 26651

Received 18th July 2017 Accepted 20th September 2017 DOI: $10.1039 / c 7 c p 04852 a$

rsc.li/pccp

\section{Surface induced smectic order in ionic liquids - an X-ray reflectivity study of $\left[\mathrm{C}_{22} \mathrm{C}_{1} \mathrm{im}\right]^{+}\left[\mathrm{NTf}_{2}\right]^{-} \dagger$}

\author{
Julian Mars, (DD ${ }^{\text {ab }}$ Binyang Hou, (D) $\ddagger^{\text {ac }}$ Henning Weiss, ${ }^{a}$ Hailong Li, ${ }^{a}$ Oleg Konovalov, ${ }^{c}$ \\ Sven Festersen, ${ }^{d}$ Bridget M. Murphy, (D) de Uta Rütt, ${ }^{f}$ Markus Bier (iD gh and \\ Markus Mezger (iD *ab
}

\begin{abstract}
Surface induced smectic order was found for the ionic liquid 1-methyl-3-docosylimidazolium bis(trifluoromethlysulfonyl)imide by X-ray reflectivity and grazing incidence scattering experiments. Near the free liquid surface, an ordered structure of alternating layers composed of polar and non-polar moieties is observed. This leads to an oscillatory interfacial profile perpendicular to the liquid surface with a periodicity of $3.7 \mathrm{~nm}$. Small angle X-ray scattering and polarized light microscopy measurements suggest that the observed surface structure is related to fluctuations into a metastable liquid crystalline $\mathrm{SmA}_{2}$ phase that was found by supercooling the bulk liquid. The observed surface ordering persists up to $157^{\circ} \mathrm{C}$, i.e. more than $88 \mathrm{~K}$ above the bulk melting temperature of $68.1^{\circ} \mathrm{C}$. Close to the bulk melting point, we find a thickness of the ordered layer of $L=30 \mathrm{~nm}$. The dependency of $L(\tau)=\Lambda \ln \left(\tau / \tau_{1}\right) v s$. reduced temperature $\tau$ follows a logarithmic growth law. In agreement with theory, the pre-factor $\Lambda$ is governed by the correlation length of the isotropic bulk phase.
\end{abstract}

\section{Introduction}

Ionic Liquids (ILs) are organic salts with a melting point below $100{ }^{\circ} \mathrm{C}$. They are typically composed of bulky and asymmetric cations, containing a positively charged moiety, polar groups and/or aliphatic side chains. The balance between Coulomb, polar, van der Waals interactions and hydrogen bonding, leads to complex structures in the liquid phase. This results in remarkable solvent properties, that are rarely found in other materials and can be tailored by the selection of a specific anion and cation combination. ${ }^{1,2}$ Over the last three decades, synthesis of new ILs

\footnotetext{
${ }^{a}$ Max Planck Institute for Polymer Research, Ackermannweg 10, 55128 Mainz, Germany.E-mail: mezger@mpip-mainz.mpg.de

${ }^{b}$ Institute of Physics and MAINZ Graduate School, Johannes Gutenberg University Mainz, 55128 Mainz, Germany

${ }^{c}$ ESRF The European Synchrotron, 71 avenue des Martyrs, 38000 Grenoble, France

${ }^{d}$ Institute of Experimental and Applied Physics, Kiel University, Leibnizstr. 19, 24098 Kiel, Germany

${ }^{e}$ Ruprecht Haensel Laboratory, Kiel University, Leibnizstr. 19, 24098 Kiel, Germany

${ }^{f}$ DESY Photon Science, Notkestr. 85, 22607 Hamburg, Germany

${ }^{g}$ Max Planck Institute for Intelligent Systems, Heisenbergstr. 3, 70569 Stuttgart, Germany

${ }^{h}$ Institute for Theoretical Physics IV, University of Stuttgart, Pfaffenwaldring 57, 70569 Stuttgart, Germany

† Electronic supplementary information (ESI) available. See DOI: 10.1039/ c7cp04852a

\# Present address: Department of Chemistry and Physical Science, School of Natural and Social Sciences, Mount Vernon Nazarene University, 800 Martinsburg Road, Mount Vernon, Ohio 43050, USA.
}

that are stable under ambient conditions opened up new fields for applications. ${ }^{3}$ Thus, ionic liquids hold immense promise as environmentally friendly replacements for conventional solvents and reaction media in chemical, energy and nano applications. ${ }^{2,4}$ Most of these applications involve processes at surfaces and interfaces in contact with other media. In the SILP (Supported Ionic Liquids Heterogeneous Phase Catalysis) process the chemical reaction takes place in an IL thin film, wetting a solid support material with high surface area. ${ }^{5-7}$ Here, one rate limiting step is the diffusion of reactants and products across the IL/gas interface. Therefore, to better understand the interfacial transport mechanisms and optimize the performance of ILs in SILP catalysis a detailed knowledge of the IL surface structure is highly desirable. ${ }^{8}$

The bulk structure of ILs was extensively studied experimentally by X-ray scattering, ${ }^{9-19}$ neutron scattering ${ }^{10,11,13,20}$ coherent anti-Stokes Raman scattering ${ }^{21}$ and by computer simulations. ${ }^{16,22-29}$ One particular feature, that draws significant attention, is the appearance of a so-called pre-peak in scattering experiments. ${ }^{16}$ These pre-peaks were observed for a wide range of ILs with aliphatic side chains longer than a butyl group. Corresponding to a length scale of a few nanometers, this peak was attributed to a high degree of intermediate range mesoscopic order. It is caused by micro phase separation in the polar networks composed of the charged moieties and domains of the non-polar alkyl side chains. ${ }^{24}$ Beyond this intermediate range mesoscopic order, long range translational order is observed in Ionic Liquid Crystals (ILCs). ${ }^{9,30-33}$ Such ILCs with 
long aliphatic side chains can form smectic mesophases over an extended temperature range. ${ }^{34,35}$ From computer simulations, a detailed understanding of their phase behavior depending on electrostatic and vdW interactions has been obtained. ${ }^{36-40}$

These bulk heterogeneities affect their molecular scale arrangement at surfaces and interfaces. Simulations of imidazolium based IL surfaces indicate that the aliphatic part of the cation points towards the interface. Nevertheless, due to the low packing of the aliphatic alkyl-chains, the aromatic ring as well as the alkyl-chains were found to be present within the uppermost surface region. ${ }^{4-43}$ Experimentally, angle-resolved $\mathrm{X}$-ray photoelectron spectroscopy shows an enrichment of the aliphatic chains at the interface of $\left[\mathrm{C}_{n} \mathrm{C}_{1} \mathrm{im}\right]^{+}$-based ILs with $n>2 .{ }^{44-49}$ Smaller anions tend to give a stronger enrichment. These observations are consistent with sum frequency generation spectroscopy showing that the imidazolium ring is parallel to the surface and the aliphatic chain is pointing toward the gas phase. ${ }^{50,51}$ Interfacial profiles with sub-nanometer resolution across free IL surfaces ${ }^{52-55}$ and buried interfaces ${ }^{56,57}$ were obtained by X-ray reflectivity (XRR) experiments. ${ }^{58,59}$ Jeon et al. observed a surface crystalline layer in $\left[\mathrm{C}_{4} \mathrm{C}_{1} \mathrm{im}\right]^{+}\left[\mathrm{PF}_{6}\right]^{-}$ using grazing incident X-ray diffraction (GIXD). ${ }^{60}$ Using resonant soft X-ray reflectivity, it was shown that the micro phase separation in ILs with long aliphatic side-chains drives an oscillatory near surface structure with a periodicity on the nanometer length scale. ${ }^{55}$ Towards the bulk, this structure is exponentially decaying with a correlation length matching the corresponding value found in the isotropic bulk liquid. Like in bulk, the oscillatory surface profiles originate from alternating regions enriched with ionic and aliphatic moieties. ${ }^{55}$ Recently, long ranged order has been found for ionic liquid films and in confinement. ${ }^{61,62}$

Here, we present a study of the 1-methyl-3-docosylimidazolium bis(trifluoromethlysulfonyl)imide $\left(\left[\mathrm{C}_{22} \mathrm{C}_{1} \mathrm{im}\right]^{+}\left[\mathrm{NTf}_{2}\right]^{-}\right.$, Fig. 1) surface. This imidazolium based IL with long $\mathrm{C}_{22}$ side chains exhibits pronounced microphase separation. ${ }^{63}$ Using $\mathrm{X}$-ray reflectivity and grazing incidence scattering, we obtain information on the temperature dependent surface structure with molecular scale resolution. Complementary information from small angle X-ray scattering, polarized light microscopy and calorimetric measurements suggest that the observed surface structure is related to fluctuations into a metastable liquid crystalline phase that was found by supercooling the bulk liquid.

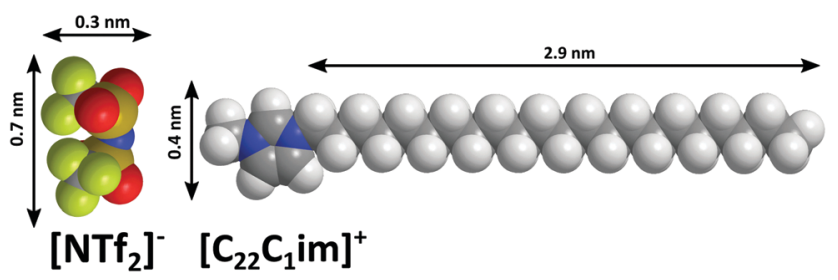

Fig. 1 Molecular structure of 1-methyl-3-docosylimidazolium bis(trifluoromethlysulfonyl)imide $\left(\left[\mathrm{C}_{22} \mathrm{C}_{1} \mathrm{im}\right]^{+}\left[\mathrm{NTf}_{2}\right]^{-}\right)$; color code: fluorine (green), oxygen (red), sulfur (yellow), nitrogen (blue), carbon (grey) and hydrogen (light grey). Arrows indicate typical intramolecular distances. Molar masses of anion and cation are $280 \mathrm{~g} \mathrm{~mol}^{-1}$ and $392 \mathrm{~g} \mathrm{~mol}^{-1}$ respectively.

\section{Materials and methods}

\subsection{Synthesis and characterization}

$\left[\mathrm{C}_{22} \mathrm{C}_{1} \mathrm{im}\right]^{+}\left[\mathrm{NTf}_{2}\right]^{-}$was synthesized from 1-methylimidazol $(\geq 99 \%$, Merck, Darmstadt), 1-bromodocosane (Santa Cruz Biotechnology, Dallas) and $[\mathrm{Li}]^{+}\left[\mathrm{NTf}_{2}\right]^{-}$(>98\%, Tokyo Chemical Industry, Tokyo). Subsequently, the IL was purified by recrystallization from a cold ethanol/water (75:25) mixture and zone melted in glass tubes under vacuum. ${ }^{64-66}$ Details on material synthesis and purification are described in ref. 67.

The temperature dependent molecular volume $V=V_{\mathrm{m}}[1+$ $\left.\alpha\left(T-T_{\mathrm{m}}\right)\right]$ of the bulk liquid was determined by pycnometry. Interpolation by linear regression yield a molecular volume of $V_{\mathrm{m}}=1.015 \mathrm{~nm}^{3}$ at the melting point $T_{\mathrm{m}}=68.1{ }^{\circ} \mathrm{C}$ and a volumetric thermal expansion coefficient $\alpha=0.745 \times 10^{-3} \mathrm{~K}^{-1}$.

Phase transition temperatures and entropies $\Delta S=\Delta H / T$ of $\left[\mathrm{C}_{22} \mathrm{C}_{1} \mathrm{im}\right]^{+}\left[\mathrm{NTf}_{2}\right]^{-}$were determined by differential scanning calorimetry (Mettler Toledo DSC-822) using scan rates between $1 \mathrm{~K} \mathrm{~min}^{-1}$ and $10 \mathrm{~K} \mathrm{~min}^{-1}$ (ESI $\dagger$ ). Equilibrium phase transition temperatures were obtained by extrapolating to zero heating and cooling rates.

Polarized light microscopy (POM) was carried out using a $10 \times$ objective and wave plate between crossed polarizer (Zeiss Photomicroscope III). The IL was contained between two glass cover slips with a sample thickness of approx. $100 \mu \mathrm{m}$. Temperature dependent measurements at a rate of approx. $20 \mathrm{~K} \mathrm{~min}^{-1}$ were performed using a heating microscope stage (Linkam THMS600).

\subsection{Bulk X-ray scattering}

Bulk X-ray scattering data was measured in transmission geometry using $\mathrm{Cu} \mathrm{K}_{\alpha}, \lambda=0.154 \mathrm{~nm}$ radiation (Rigaku MicroMax 007 X-ray generator, Osmic Confocal Max-Flux curved multilayer optics). The IL was contained in an $1 \mathrm{~mm}$ thick glass capillary (wall thickness $0.01 \mathrm{~mm}$ ). Capillaries were placed in a nitrogen stream (Oxford Cryostream 700) and a temperature controlled copper holder inside a vacuum tube for wide and small angle scattering experiments respectively. Scattering data was recorded on an online image plate detector (Mar345, MarResearch) at a sample-detector distance of $352 \mathrm{~mm}$ and $2089 \mathrm{~mm}$. Background from high energy radiation, was removed by a Laplace filter based masking algorithm. Scattering patterns $I(q) v s$. momentum transfer $q=4 \pi / \lambda \sin (\theta)$ were obtained by radial averaging of the $2 \mathrm{D}$-scattering patterns.

\subsection{X-ray reflectivity}

$\mathrm{X}$-ray reflectivity (XRR) experiments were performed at the liquid interface scattering apparatus (LISA) at P08, PETRA III, DESY Hamburg. ${ }^{68}$ The size of the focussed X-ray beam $(18 \mathrm{keV}$ $\mathrm{X}$-ray energy, $\lambda=0.069 \mathrm{~nm}$ ) was $500 \mu \mathrm{m} \times 8 \mu \mathrm{m}$ at the sample position. Scattering pattern was collected on a hybride pixel detector (Dectris Eiger 1M, $75 \mu \mathrm{m} \times 75 \mu \mathrm{m}$ pixel size) at $1.2 \mathrm{~m}$ sample-detector distance. The liquid was contained in a circular PTFE sample trough (1 mm depth, $9 \mathrm{~cm}$ diameter). The trough was placed in a temperature controlled (Julabo FN25-HE) stainless steel (EN 1.4571) chamber (stability $\pm 0.006 \mathrm{~K}$ ) under helium 


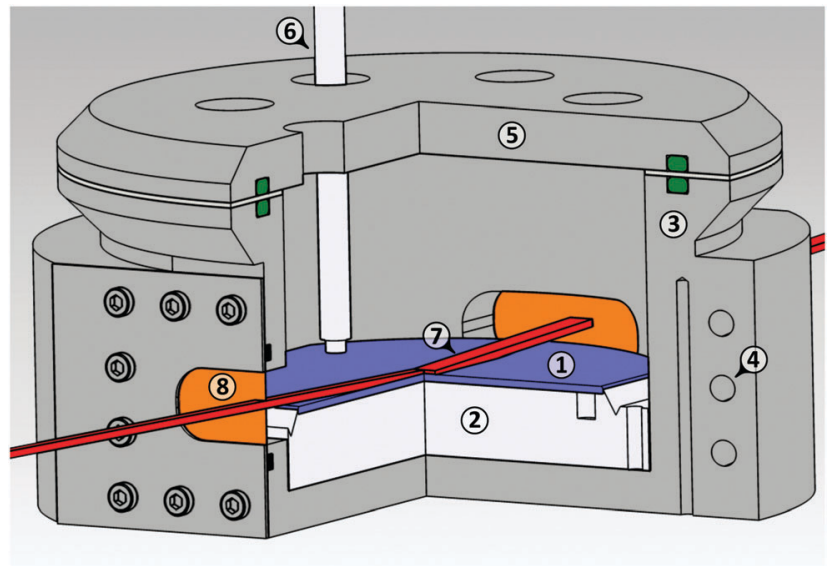

Fig. 2 Sample cell for XRR experiments. The IL (1, purple) is contained in a PTFE trough (2, white). The outer steel cell $(3$, gray) is temperature controlled by a fluid circulating trough flow channels (4) and resistive heating pads ( $80 \mathrm{~W}$, not shown). The lid (5, grey) contains feedthroughs for PT1000 temperature sensors (6, white) and helium in- and outlet. Windows for the incident and reflected $X$-ray beam $(7$, red, size and angles exaggerated) were made of $50 \mu \mathrm{m}$ thick Kapton foils (8, orange).

atmosphere (Fig. 2). To improve the temperature homogeneity at the IL/helium interface, the steel cell was packed in $5 \mathrm{~cm}$ thick melamine isolation foam.

The PTFE trough was cleaned in Piranha solution (3 parts $\mathrm{H}_{2} \mathrm{SO}_{4} 98 \%$, 1 part hydrogen peroxide $30 \%$ ) for at least 20 minutes, thoroughly rinsed with ultrapure water, and dried in a nitrogen stream. $\left[\mathrm{C}_{22} \mathrm{C}_{1} \mathrm{im}\right]^{+}\left[\mathrm{NTf}_{2}\right]^{-}$was filled into the heated trough at $90{ }^{\circ} \mathrm{C}$ until a convex meniscus was formed.

Molecular resolution is obtained by recording XRR patterns up to a sufficiently high momentum transfers $q_{z}$ perpendicular to the sample surface. Therefore, the specular reflected X-ray beam was recorded for incident angles $\alpha_{\mathrm{i}} \leq 1.9^{\circ}$. This corresponds to momentum transfers $q_{z}=4 \pi / \lambda \sin \alpha_{\mathrm{i}} \leq 6 \mathrm{~nm}^{-1}$. Specular intensities were extracted from the $2 \mathrm{D}$ patterns by integration over an area of $40 \times 40$ detector pixels. The background signal predominantly originates from the diffuse scattering contributions of the bulk liquid. It exhibits an approximately concentric intensity distribution around the primary beam axis. Therefore, background intensities were measured at a horizontal offset of 20 pixels and a vertical offset, adjusted to keep the total scattering angle $2 \theta$ for the specular reflection and the background equal. XRR segments measured at different absorber settings were merged and interpolated on an equidistant $q_{z}$-grid.

\subsection{Grazing incidence scattering}

Grazing incident X-ray scattering experiments were performed at the six-circle liquid diffractometer at beamline ID10-EH1 at the European Synchrotron Radiation Facility (ESRF) in Grenoble, France using an energy of $8 \mathrm{keV}(\lambda=0.155 \mathrm{~nm})$. The IL was contained in a circular stainless steel trough (120 $\mathrm{mm}$ diameter, $1 \mathrm{~mm}$ depths). To reduce the background signal from air scattering the sample was kept under helium atmosphere during X-ray irradiation. First, the sample was heated to $96{ }^{\circ} \mathrm{C}$ followed by gradual cooling to the desired temperature with a rate of $0.25 \mathrm{~K} \mathrm{~min}^{-1}$. Signals were collected by a gas filled multi-channel detector (Gabriel $150 \mathrm{~mm}$ ) in vertical orientation. Grazing incident X-ray scattering patterns were recorded at an incident angle $\alpha_{\mathrm{i}}=0.12^{\circ}$ i.e. $80 \%$ of the measured critical angle of total reflection $\alpha_{c}=0.15^{\circ}$.

\section{Analysis}

\subsection{X-Ray reflectivity}

XRR can provide information on the density profile $\rho(z)$ across liquid surfaces on a molecular length scale. For an ideal sharp surface profile, the so-called Fresnel reflectivity $R_{\mathrm{F}}\left(q_{z}\right)$ is obtained.

$$
\begin{aligned}
& R_{\mathrm{F}}\left(q_{z}\right)=\left|\frac{q_{z}-\sqrt{q_{z}^{2}-q_{\mathrm{c}}^{2}}}{q_{z}+\sqrt{q_{z}^{2}-q_{\mathrm{c}}^{2}}}\right|^{2} \\
& q_{\mathrm{c}}^{2}=\frac{16 \pi^{2}}{\lambda^{2}}\left(1-n^{2}\right) \approx \frac{16 \pi r_{\mathrm{e}} f}{V_{\mathrm{m}}}
\end{aligned}
$$

Here, $r_{\mathrm{e}}$ denotes the classical electron radius. The complex refractive index $n$ for hard X-rays is close to unity i.e. $|n-1| \ll 1$. Values can be obtained from tabulated energy dependent molecular X-ray scattering factors $f \cdot{ }^{69-71}$ For large momentum transfers $q_{z} \gg q_{\mathrm{c}}$ and a small X-ray absorption cross section of the material i.e. $\Im(f) \ll \Re(f)$, eqn (1a) is well approximated by

$$
R_{\mathrm{F}}\left(q_{z}\right) \approx\left(\frac{\Re\left(q_{\mathrm{c}}\right)}{2 q_{z}}\right)^{4} .
$$

Hence, $R_{\mathrm{F}}$ rapidly decays by the fourth power of $q_{z} \cdot{ }^{72,73}$

Deviations from an ideal surface cause modulations in the Fresnel normalized XRR patterns. Within the Born approximation, the XRR pattern $R\left(q_{z}\right)$ is linked to its corresponding real space electron density profile $\rho_{\mathrm{e}}(z)$ across the liquid surface via Fourier transformation ${ }^{72,73}$

$$
R(q)=\frac{R_{\mathrm{F}}(q)}{\left(\rho_{-\infty}-\rho_{+\infty}\right)^{2}}\left|\int \frac{\mathrm{d} \rho(z)}{\mathrm{d} z} \mathrm{e}^{\mathrm{i} q_{z} z} \mathrm{~d} z\right|^{2}
$$

where $\rho_{-\infty}$ and $\rho_{+\infty}$ is the electron density of the vapor phase and bulk liquid respectively. However, due to the phase problem a direct inversion of eqn (3) to obtain the density profile $\rho_{\mathrm{e}}(z)$ from an experimental reflectivity pattern $R\left(q_{z}\right)$ is in the general case not possible. ${ }^{74,75}$ Therefore, in most cases model profiles $\rho_{\mathrm{e}}(z)$ have to be constructed. Subsequently, the free model parameters can be determined from the experimental data by fitting.

\subsection{Model profiles and fitting procedure}

Electron density profiles $\rho_{\mathrm{e}}(z)$ across IL surfaces were made up of different contributions:

$$
\rho_{\mathrm{e}}(z)=\rho_{\mathrm{e}}^{\mathrm{b}} \Phi\left(\frac{z}{\sigma_{\mathrm{s}}}\right)[1+\phi(z) \psi(z)]
$$


To limit the number of free parameters, the temperature dependent bulk electron density $\rho_{\mathrm{e}}^{\mathrm{b}}$ was independently determined by pycnometry. Following Névot and Croce, the cumulative normal distribution function

$$
\Phi(x):=\frac{1}{2}\left[1+\operatorname{erf}\left(\frac{x}{\sqrt{2}}\right)\right]
$$

accounts for the intrinsic molecular scale surface roughness $\sigma_{\mathrm{s}} \cdot{ }^{72,76}$ Deviations from this ideal surface structure are encoded in the last term of eqn (4). Here, $\psi(z)$ is an oscillatory function, modulated by an envelope $\phi(z)$.

The oscillatory function with periodicity $d$ is expanded in a series

$$
\psi(z)=\sum_{j=1}^{\infty} a_{j} \exp \left(-\frac{z}{\xi_{j}}\right) \sin \left(2 \pi j \frac{z-z_{0}}{d}\right) .
$$

Without loss of generality, we can set the coefficients $a_{1}=1$ and $\xi_{1} \rightarrow \infty$. Taking into account first and second order terms only, perfect fits to the experimental XRR data were found. This oscillatory near surface structure is motivated by the crystal structure of $\left[\mathrm{C}_{22} \mathrm{C}_{1} \mathrm{im}\right]^{+}\left[\mathrm{NTf}_{2}\right]^{-, 63}$ molecular dynamic simulations, ${ }^{26,29}$ and liquid structure factor calculations ${ }^{25}$ of related materials. Maxima in $\psi(z)$ account for the ionic regions composed of the imidazolium rings and $\left[\mathrm{NTf}_{2}\right]^{-}$anions. These molecular moieties exhibit an electron density above the bulk average $\rho_{\mathrm{e}}^{\mathrm{b}}$. On the other hand, the location of the cations aliphatic side chains correspond to the minima of $\psi(z)$. In previous studies, similar oscillatory near surface structures have been observed for different ILs. ${ }^{53-55}$

The oscillatory function $\psi(z)$ in eqn (6) corresponds to the microscopic structure of smectic layers of the IL moieties. The envelope $\phi(z)$ in eqn (4) plays the role of a locally varying smectic order parameter profile. Within a simple variant of the Landau-de Gennes formalism, ${ }^{77}$ one can determine that smectic order parameter profile $\phi(z)$ of a smectic surface layer of thickness $L$ in between a vapor phase and the bulk liquid. Here, only the leading terms

$$
\phi(z)= \begin{cases}S^{0}+S^{-} \sinh \left(\frac{z}{\xi_{\mathrm{s}}}\right) & \text { if } z \leq L \\ B \exp \left(-\frac{z}{\xi_{\mathrm{b}}}\right) & \text { if } z>L\end{cases}
$$

with the free parameters for the amplitude $S^{-}$, decay length $\xi_{\mathrm{s}}$, and surface layer thickness $L$ are considered. The amplitudes $S^{0}$ and $B$ were determined by the continuity and differential continuity condition at $z=L$. To further reduce the number of free parameters, the bulk correlation length $\xi_{\mathrm{b}}$ was independently determined by X-ray scattering.

Reflectivity curves were numerically calculated using the Parratt formalism after dividing the profile into $0.05 \mathrm{~nm}$ slabs of constant density. ${ }^{72,78}$ Dispersion effects were included using $\mathrm{X}$-ray form factors from Henke et al. ${ }^{69}$ Density profiles were extracted from the experimental XRR data by parameter refinement using a simulated annealing algorithm. ${ }^{79}$ Damping of the specular reflectivity due to capillary wave roughness of the liquid surface ${ }^{80,81}$ was taken into account by

$$
\Gamma_{\mathrm{cw}}(q)=\exp \left[-\frac{k_{\mathrm{B}} T}{2 \pi \gamma} \ln \left(\frac{q_{\mathrm{m}}}{\Delta q}\right) q_{z}^{2}\right]
$$

assuming a surface tension $\gamma=30 \mathrm{mN} \mathrm{m}^{-1}, 82$ a molecular cutoff $q_{\mathrm{m}}=\pi \mathrm{nm}^{-1}$ and a resolution of $\Delta q=1.3 \times 10^{-3} q_{z}$. However, changes in surface tension and molecular cutoff give comparable quality fits with similar density profiles. This is explained by parameter coupling between the intrinsic surface roughness $\sigma_{\mathrm{s}}$, and the capillary wave damping factor $\Gamma_{\mathrm{cw}}(q)$.

\subsection{Surface thermodynamics}

Within a generic approach, interface induced phase transitions such as wetting, interfacial premelting, or surface induced ordering can be described by a continuum model. ${ }^{83-85}$ In this model, a thin surface layer of thickness $L$ is wetting the bulk. In the case of surface induced ordering, the bulk consists of an isotropic liquid (l). The surface layer (s), forming at the liquid/ vapor (v) interface, exhibits a higher degree of order. This leads to a negative surface excess entropy. ${ }^{86}$ In the standard continuum model, the interfacial free energy of the system is expressed by an effective thickness-dependent $\gamma(L)$.

$$
\begin{gathered}
\gamma(L)=\gamma_{\mathrm{lv}}+\varphi(L) \Delta \gamma \\
\Delta \gamma=\gamma_{\mathrm{ls}}+\gamma_{\mathrm{sv}}-\gamma_{\mathrm{lv}} \\
\varphi(L)=1-\mathrm{e}^{-\frac{L}{\Lambda}}
\end{gathered}
$$

Here, $\Delta \gamma$ is the deviation from Antonow's rule, coupling the interfacial free energies between the vapor with the bulk liquid $\left(\gamma_{\mathrm{lv}}\right)$ and the surface phase $\left(\gamma_{\mathrm{sv}}\right)$, and between the bulk liquid and the surface phase $\left(\gamma_{\mathrm{ls}}\right)$, respectively. For large layer thicknesses $L \rightarrow \infty$, one obtains $\varphi=1$. This implies, that the total surface energy $\gamma(L)$ is given by the sum of two non-interacting (ls) and (sv) interfaces. Above the onset temperature $T_{1}$ where no ordered surface layer exists, we find $\varphi=0$ and $\gamma=\gamma_{\mathrm{lv}}$. For intermediate thicknesses, the transition between these two cases is mediated by an exponential function with decay length $\Lambda$.

By minimization of the total free energy of the system, a logarithmic growth law of the ordered surface layer thickness $L$ vs. reduced temperature $\tau=\frac{T-T_{0}}{T_{0}}$ is obtained.

$$
\begin{gathered}
L(\tau)=\Lambda \ln \left(\frac{\tau_{1}}{\tau}\right) \\
\tau_{1}=\frac{\Delta \gamma V_{\mathrm{m}}}{\Delta H_{\mathrm{m}} \Lambda}
\end{gathered}
$$

Above the onset temperature $\tau_{1}$ the ordered surface layer vanishes. This transition temperature is determined by the molar latent heat of fusion $\Delta H_{\mathrm{m}}$ between the isotropic bulk and ordered surface phase per molar volume $V_{\mathrm{m}}$. Approaching the bulk transition temperature $T_{0}$, the ordered surface layer thickness diverges. 


\section{Results and discussion}

\subsection{Bulk structure}

Upon heating, $\left[\mathrm{C}_{22} \mathrm{C}_{1} \mathrm{im}\right]^{+}\left[\mathrm{NTf}_{2}\right]^{-}$shows a phase transition from the crystalline phase to an isotropic liquid at $T_{\mathrm{m}}=68.1$ (Fig. 3 and Fig. S1, ESI $\dagger$ ). However, three phase transitions were observed by DSC during cooling. For the peak at $T_{\mathrm{LC}}=67.1^{\circ} \mathrm{C}$ a transition entropy of $\Delta S_{\mathrm{LC}}=2.5 \mathrm{~J} \mathrm{~mol}^{-1} \mathrm{~K}^{-1}$ was found (Fig. 3 and Fig. S2, ESI $\dagger$ ). This resembles typical values for the formation of liquid crystalline mesophases. ${ }^{87}$ Similarly, a tendency to form liquid crystalline-like structures has been proposed for long aliphatic side chains by MS-CG simulations. ${ }^{36,37}$ The transition temperature is only about $1 \mathrm{~K}$ below the melting point. No corresponding transition was observed during heating. Therefore, we conclude that the transition is related to a metastable phase. For other imidazolium based ILs with long aliphatic $\mathrm{C}_{16}$ to $\mathrm{C}_{18}$ side chains and smaller $[\mathrm{Cl}]^{-},\left[\mathrm{BF}_{4}\right]^{-}$and $\left[\mathrm{PF}_{6}\right]^{-}$anions thermodynamically stable $\mathrm{SmA}_{2}$-phases have been found. , $^{9,30-33}$

Indeed, a focal conic texture, indicating a smectic A liquid crystalline mesophase, was observed in POM (Fig. 4c). ${ }^{63}$ Together with the SAXS data (Fig. 4) and the dimensions of the molecular moieties (Fig. 1) this mesophase is identified as a $\mathrm{SmA}_{2}$ liquid crystalline phase. While the absence of bâtonnets typically is linked to nematic to smectic phase transitions ${ }^{88}$ no signs for a nematic phase was found by DSC, POM and X-ray scattering. At $58.4{ }^{\circ} \mathrm{C}$ and $57.7^{\circ} \mathrm{C}$ a double peak was observed in DSC. The higher temperature peak was attributed to the smectic to crystal transition. Its transition temperature strongly varied for different DSC measurements. The second peak is likely related to a solid-solid transition between two different crystal structures.

Above the melting point, the X-ray scattering patterns of $\left[\mathrm{C}_{22} \mathrm{C}_{1} \mathrm{im}\right]^{+}\left[\mathrm{NTf}_{2}\right]^{-}$exhibit three diffuse peaks at $q_{0}=1.7 \mathrm{~nm}^{-1}$, $7.9 \mathrm{~nm}^{-1}$ and $12.9 \mathrm{~nm}^{-1}$ (Fig. 4a). The two peaks II and III at large momentum transfer $q$ were associated with charge alternation and adjacency correlations. ${ }^{15,29}$ From the peak position, a periodicity $2 \pi / q_{0} \approx 3.6 \mathrm{~nm}$ is estimated at $T=96{ }^{\circ} \mathrm{C}$. Having a

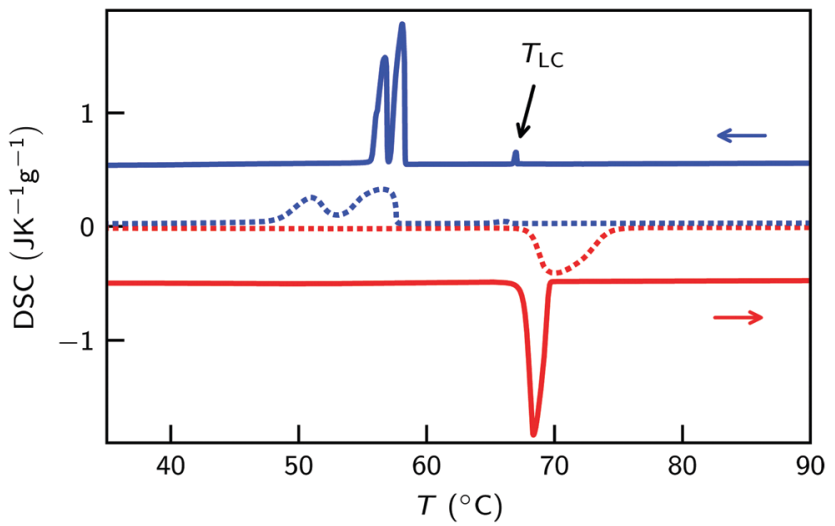

Fig. $3 \mathrm{DSC}$ of $\left[\mathrm{C}_{22} \mathrm{C}_{1} \mathrm{im}\right]^{+}\left[\mathrm{NTf}_{2}\right]^{-}$measured during heating (red) and cooling (blue) with a temperature rate of $1 \mathrm{~K} \mathrm{~min}^{-1}$ (solid lines) and $10 \mathrm{~K} \mathrm{~min}^{-1}$ (dashed lines). Arrows indicate the formation of a liquid crystalline smectic mesophase. Curves for $1 \mathrm{~K} \mathrm{~min}^{-1}$ are shifted vertically by $\pm 0.5 \mathrm{~J} \mathrm{~K}^{-1} \mathrm{~g}^{-1}$ for clarity.

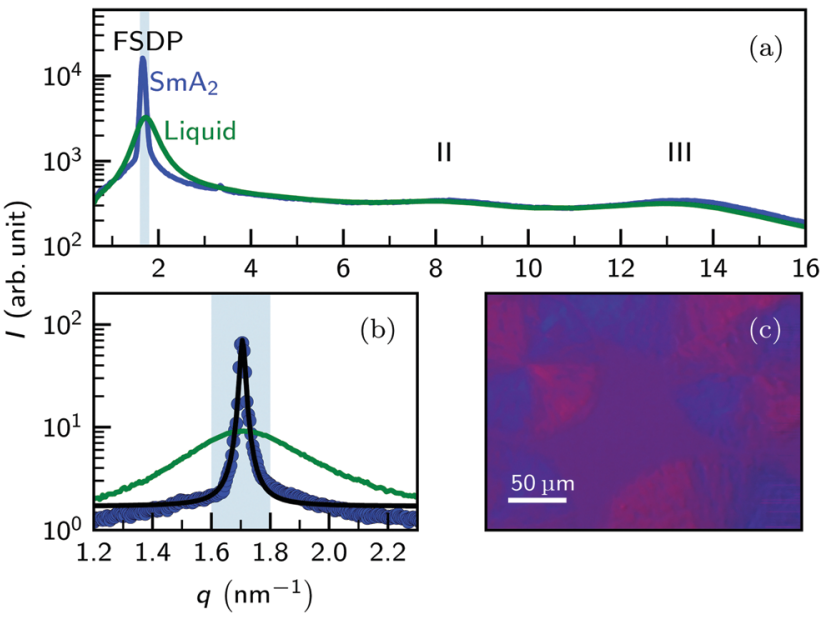

Fig. 4 Liquid crystalline smectic $\left[\mathrm{C}_{22} \mathrm{C}_{1} \mathrm{im}\right]^{+}\left[\mathrm{NTf}_{2}\right]^{-}$mesophase. (a) Comparison of $X$-ray scattering patterns in the bulk liquid phase (green, $T=96^{\circ} \mathrm{C}$ ) and the mesophase obtained by rapid cooling (blue). (b) SAXS pattern of the FSDP at $69.8^{\circ} \mathrm{C}$ (liquid, green line) and $59.8^{\circ} \mathrm{C}\left(\mathrm{SmA}_{2}\right.$, blue circles). The black line indicates a fit to a pseudo-Voigt profile. (c) Polarized light microscopy image at $60.4{ }^{\circ} \mathrm{C}$, showing a focal conical texture.

periodicity similar to the molecular length scale (Fig. 1), the origin of the first sharp diffraction peak (FSDP) can be identified with the polarity alternation i.e. microphase separation of the ionic and aliphatic moieties. ${ }^{12,25,26,29}$

Quantitative analysis by fitting a generalized Teubner-Strey model to the scattering patterns yield a periodicity $d_{\mathrm{b}}(T)=3.74 \mathrm{~nm}$ $-0.348 \times 10^{-2} \mathrm{~nm} \mathrm{~K}^{-1}\left(T-T_{\mathrm{m}}\right)$ and a correlation length $\xi_{\mathrm{b}}(T)=$ $4.79 \mathrm{~nm}-0.0298 \mathrm{~nm} \mathrm{~K}^{-1}\left(T-T_{\mathrm{m}}\right)$. A detailed X-ray scattering study of the $\left[\mathrm{C}_{22} \mathrm{C}_{1} \mathrm{im}\right]^{+}\left[\mathrm{NTf}_{2}\right]^{-}$bulk structure in comparison to $\left[\mathrm{C}_{18} \mathrm{C}_{1} \mathrm{im}\right]^{+}[\mathrm{FAP}]^{-},\left[\mathrm{C}_{18} \mathrm{C}_{1} \mathrm{im}\right]^{+}\left[\mathrm{NTf}_{2}\right]^{-},\left[\mathrm{C}_{18} \mathrm{C}_{1} \mathrm{im}\right]^{+}\left[\mathrm{NNf}_{2}\right]^{-}$and $\left[\mathrm{C}_{22} \mathrm{C}_{1} \mathrm{im}\right]^{+}\left[\mathrm{NNf}_{2}\right]^{-}$is found in ref. 67.

Upon rapid cooling below the $\mathrm{SmA}_{2}$ transition temperature $T_{\mathrm{LC}}$, the FSDP becomes much sharper. The periodicity $d_{\mathrm{LC}}=$ $2 \pi / q_{0}=3.68 \mathrm{~nm}$ was found to be only $1.6 \%$ shorter then the value in the isotropic liquid. Albeit much weaker in intensity, a 2nd order reflection is observed at $2 q_{0}=3.4 \mathrm{~nm}^{-1}$. Analysis of high-resolution SAXS data by fitting a pseudo-Voigt function to the FSDP reveals a total FWHM of $0.0185 \mathrm{~nm}^{-1}$ (Fig. 4a). This value is close to the resolution limit of the instrument. From the Scherrer formula we estimate domain sizes $\geq 0.7 \mu \mathrm{m}$ i.e. long ranged translational order. In contrast, the intensity, position and shape of the high- $q$ peaks II and III remain almost unchanged. Together with the small change in the position of the FSDP, this indicates a strong structural similarity of the liquid crystalline phase and the mesoscopic structure found in the liquid phase. $^{19}$

\subsection{Surface structure}

Density profile $\rho_{\mathrm{e}}(z)$ across the liquid surface with molecular scale resolution were extracted from the XRR patterns. Fig. 5a shows XRR curves $R\left(q_{z}\right)$ versus momentum transfer of the $\left[\mathrm{C}_{22} \mathrm{C}_{1} \mathrm{im}\right]^{+}\left[\mathrm{NTf}_{2}\right]^{-}$surface for different temperatures above the bulk melting point. To highlight features originating from density modulations adjacent to the liquid surface, data was 

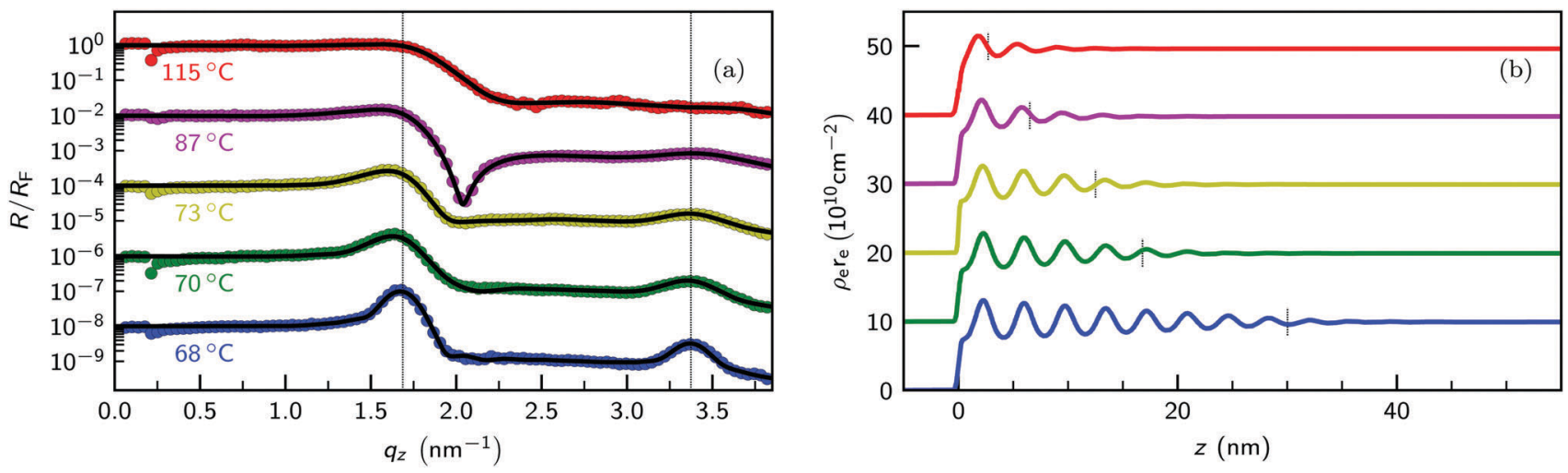

Fig. 5 (a) Temperature dependent XRR curves of the $\left.\left[\mathrm{C}_{22} \mathrm{C}_{1} \mathrm{im}\right]^{+}[\mathrm{NTf}]_{2}\right]^{-}$surface normalized to the Fresnel reflectivity $R_{\mathrm{F}}\left(q_{z}\right)$ (symbols) and calculated patterns (solid lines). Vertically dashed lines at $2 \pi / d_{\mathrm{s}}=1.69 \mathrm{~nm}^{-1}$ and $3.37 \mathrm{~nm}^{-1}$ indicate the positions of the 1st and 2nd order quasi-Bragg peaks. (b) Electron density profile $\rho_{\mathrm{e}}(z)$ obtained by fitting eqn (4) to the experimental XRR data. Horizontal tics indicate the layer thickness $L$ of the ordered structure near the IL surface. Curves measured at $115^{\circ} \mathrm{C}$ (red), $87^{\circ} \mathrm{C}$ (purple), $73^{\circ} \mathrm{C}$ (yellow), $70^{\circ} \mathrm{C}$ (green), and $68^{\circ} \mathrm{C}$ (blue) are vertically shifted for clarity.

normalized to the Fresnel reflectivity $R_{\mathrm{F}}\left(q_{z}\right)$ of an structure-less surface (eqn (1)). For $\left[\mathrm{C}_{22} \mathrm{C}_{1} \mathrm{im}\right]^{+}\left[\mathrm{NTf}_{2}\right]^{-}$we calculate a critical momentum transfer of total reflection $\Re\left(q_{\mathrm{c}}\right)=0.23 \mathrm{~nm}^{-1} .{ }^{69}$ This corresponds to a critical incidence angle $\alpha_{\mathrm{c}}=0.070^{\circ}$ at $18 \mathrm{keV}$. From the experimental data we extract a critical momentum transfer $q_{\mathrm{c}}=0.21 \mathrm{~nm}^{-1}$. This agrees well with the value calculated from eqn (1b). As expected, below $q_{\mathrm{c}}$ we obtain a reflectivity close to unity. Spikes in the region around $q_{z} \approx q_{\mathrm{c}}$ are caused by the $R_{\mathrm{F}}$ normalization with minute uncertainties in the calculated critical momentum transfer $q_{\mathrm{c}}$.

Deviations from an ideal surface cause modulations in the Fresnel normalized XRR patterns (Fig. 5). For the highest temperature of $115{ }^{\circ} \mathrm{C}$ (red symbols), a step-like reflectivity curve is obtained. At lower temperatures, this step gradually transforms into a dip (purple curve, $87^{\circ} \mathrm{C}$ ). These modulations are directly linked to changes in the density profiles across the IL surface by Fourier transformation (eqn (3)). Therefore, the observed dip, resembling an inverted Lorentzian peak, correspond to an exponentially damped oscillatory density profile across the IL surface. ${ }^{57,89}$ Qualitatively similar XRR curves were obtained for $\left[\mathrm{C}_{18} \mathrm{C}_{1} \mathrm{im}\right]^{+}[\mathrm{FAP}]^{-} .{ }^{55}$ Using resonant scattering techniques, the oscillatory surface profile was attributed to alternating layers. They are composed of aliphatic side chains and ionic moieties i.e. the anions and positively charged imidazolium rings. The periodicity $d_{\mathrm{s}}=2 \pi / q_{0} \approx 3 \mathrm{~nm}$ of the oscillatory surface profiles estimated from the peak position $q_{0}=2 \mathrm{~nm}^{-1}$ is similar to the bulk value $d_{\mathrm{b}}$.

Below $73{ }^{\circ} \mathrm{C}$ (yellow symbols) two Bragg-like peaks emerge in the XRR curves. They correspond to 1st and 2nd order reflections at $q_{0}=1.68 \mathrm{~nm}^{-1}$ and $2 q_{0}=3.35 \mathrm{~nm}^{-1}$, respectively. As temperature decreases towards the transition temperature $T_{\mathrm{LC}}$ where long ranged translational order was observed in bulk, these peaks get sharper and their intensities increase (green and blue symbols). Like the dip, these peaks originate from an oscillatory surface profile. However, the appearance of two distinct Bragg-like 1st and 2nd order peaks indicate an increasing surface order. In analogy, in the SAXS bulk measurements the 2nd order FSDP was only observed in the liquid crystalline smectic phase.
This suggests the formation of surface induced smectic order with a smectic layer of thickness $L$ wetting the isotropic liquid bulk phase.

Fig. 6a shows the grazing incidence scattering patterns recorded from the $\left[\mathrm{C}_{22} \mathrm{C}_{1} \mathrm{im}\right]^{+}\left[\mathrm{NTf}_{2}\right]^{-}$surface at $70.2{ }^{\circ} \mathrm{C}$. At the grazing angle $\alpha_{\mathrm{i}}=0.12^{\circ}$, corresponding to $80 \%$ of the critical
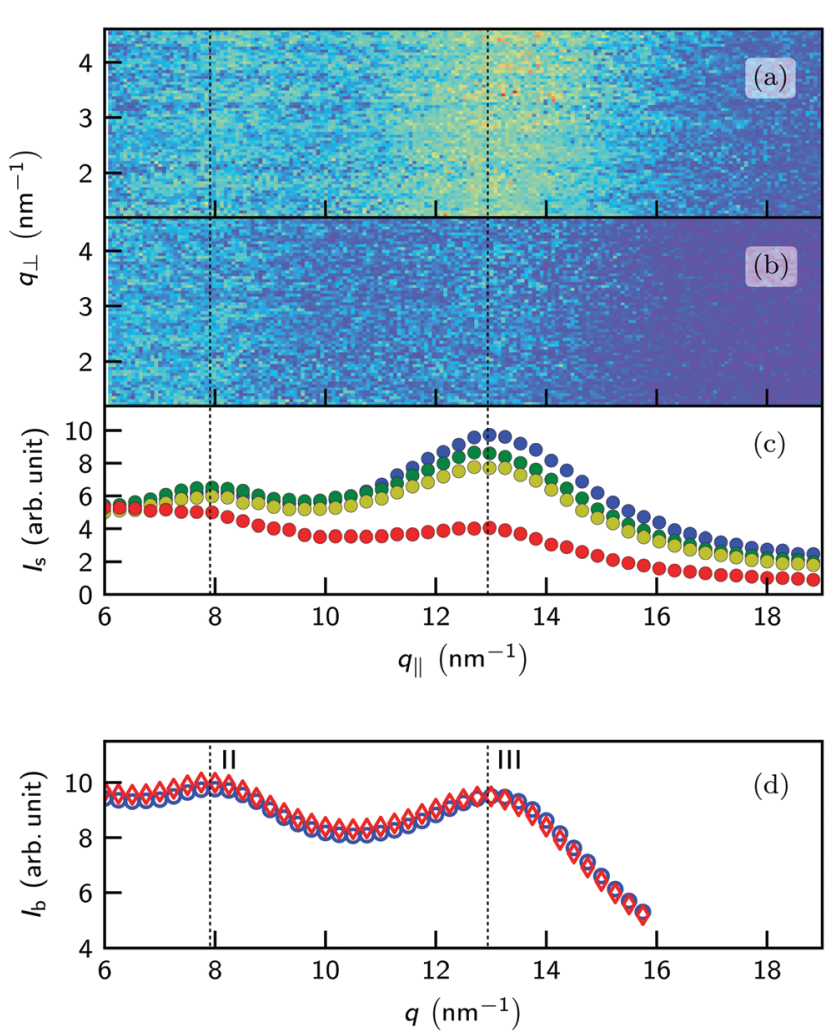

Fig. 6 (a) Grazing incident X-ray scattering patterns of $\left[\mathrm{C}_{22} \mathrm{C}_{1} \mathrm{im}\right]^{+}[\mathrm{NTf}]^{-}$ at (a) $70.2{ }^{\circ} \mathrm{C}$ and (b) $92.0{ }^{\circ} \mathrm{C}$. (c) $I_{s}\left(q_{\|}\right)$at $92.0^{\circ} \mathrm{C}$ (red), $76.2^{\circ} \mathrm{C}$ (yellow), $72.2^{\circ} \mathrm{C}$ (green) and $70.2{ }^{\circ} \mathrm{C}$ (blue). (d) Bulk scattering $l_{\mathrm{b}}(q)$ at $69.8^{\circ} \mathrm{C}$ (blue circles) and $95.8^{\circ} \mathrm{C}$ (red diamonds). Vertical lines indicate the position of the $2 \mathrm{nd}$ and $3 \mathrm{rd}$ maxima in the bulk scattering at $7.9 \mathrm{~nm}^{-1}$ and $12.9 \mathrm{~nm}^{-1}$, respectively. 
angle of total reflection, the X-ray beam does not penetrate into the bulk liquid. Instead, an evanescent wave with a decay length of approx. $10 \mathrm{~nm} \approx 3 d_{\mathrm{s}}$ is formed. Therefore, in the grazing incidence experiments the bulk signal is strongly suppressed. This allows to detect the relatively weak scattering from the near surface region where oscillatory density profiles were observed. Long-range lateral order at the surface, e.g. a 2D crystalline structure, gives rise to sharp streaks along $q_{\perp}$ at distinct $q_{\|}$ values. $^{90}$

However, in contrast to the experiments by Jeon et al. on $\left[\mathrm{C}_{4} \mathrm{C}_{1} \mathrm{im}\right]^{+}\left[\mathrm{PF}_{6}\right]^{-60}$ at all temperatures no indications for longranged in-plane order have been found in our experiments. Instead, two broad diffuse peaks are observed (Fig. 6c). Their positions and widths are similar to the peaks II and III observed in bulk (Fig. 6d). However, unlike in bulk the relative peak intensity is strongly changing with temperature. Upon cooling, the intensity of peak III at $13 \mathrm{~nm}^{-1}$ is significantly increasing. In contrast, the corresponding bulk peak intensity remains almost unchanged. ${ }^{18}$ At low temperatures, the long axis of the smectic fluctuations adjacent to the surface are preferably aligned parallel to the surface normal. Thus, the in-plane scattering signals in the $q_{\|}$-direction originating from charge alternation (peak II) and adjacency correlations (peak III) are enhanced. When the thickness of the smectic layer $L$ reaches the decay length of the evanescent X-ray wave the peak intensities saturate. This texture effect affects only the peak intensities, leaving their position and shape unchanged with respect to the isotropic bulk liquid. This observation confirms our interpretation that the structure of the $\left[\mathrm{C}_{22} \mathrm{C}_{1} \mathrm{im}\right]^{+}\left[\mathrm{NTf}_{2}\right]^{-}$surface above its melting point is governed by fluctuations of the metastable smectic mesophase rather than by formation of a 2D surface crystal.

\subsection{Growth law}

To obtain quantitative density profiles across the IL surface, the experimental XRR data was analyzed using eqn (4). For all temperatures, the experimental XRR pattern is perfectly reproduced by the curves calculated from the model profiles (Fig. 5). Model parameters of the best fits are summarized in Table 1. Detailed analysis showed that the values extracted for the smectic layer thickness $L$ are robust parameters (ESI $\dagger$ ).

Horizontal tics in Fig. 5b indicate the layer thickness $L$ of the ordered structure near the IL surface. For $z \leq L$, the envelope $\phi(z)$ of the density profile is given by eqn (7), whereas for $z>L$ the envelope is exponentially decaying with the bulk correlation length $\xi_{\mathrm{b}}$ determined by X-ray scattering. ${ }^{67}$

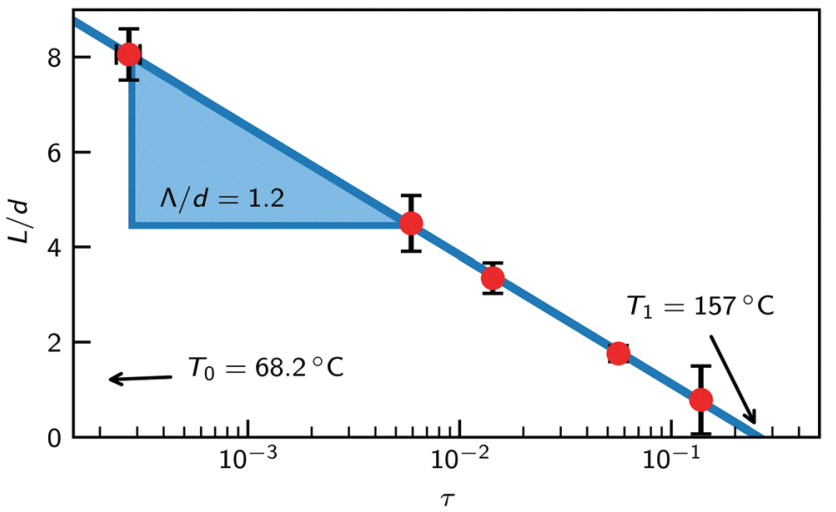

Fig. 7 Smectic wetting layer thickness $L$ from fits (red circles) and fit to eqn (10a) (blue line) vs. reduced temperature $\tau=\left(T-T_{0}\right) / T_{0}$.

Fig. 7 shows the layer thickness $L / d$ of the normalized surface structure divided by its periodicity $d v s$. reduced temperature $\tau$ (red circles). The blue line is a fit to the theoretically predicted growth law assuming exponentially decaying short range interactions (eqn (10a)). Approaching the bulk transition temperature $T_{0}$, the surface layer thickness $L$ is diverging. From the fit we obtain $T_{0}=68.2{ }^{\circ} \mathrm{C}$.

This value agrees well with the transition temperature $T_{\mathrm{LC}}=67.1{ }^{\circ} \mathrm{C}$ of the metastable smectic bulk phase determined from DSC measurements. On the other hand, surface induced ordering is found only below $\tau=0.26$. This corresponds to an onset temperature $T_{1}=157{ }^{\circ} \mathrm{C}$. Above this temperature, the oscillatory structure near interfaces decays exponentially with a decay length given by the corresponding bulk correlation length $\xi_{\mathrm{b}}{ }^{91}$

For the structurally similar imidazolium based IL $\left[\mathrm{C}_{18} \mathrm{C}_{1} \mathrm{im}\right]^{+}[\mathrm{FAP}]^{-}$no such surface ordered structures were found in a previous XRR study. ${ }^{55}$ In contrast, over the entire accessible temperature range the decay length at the surface was found to be equal to the bulk correlation length. However, unlike for $\left[\mathrm{C}_{22} \mathrm{C}_{1} \mathrm{im}\right]^{+}\left[\mathrm{NTf}_{2}\right]^{-}$no indications for metastable liquid crystalline mesophases have been found in this system.

In literature, at least three distinct types of interface induced smectic order are discussed: discrete, continuous, and continuous with a prewetting layer. Discrete interface induced smectic order has been found for several liquid crystals at the free surface, ${ }^{92-94}$ in pores, ${ }^{95}$ and by simulation. ${ }^{96}$ In these systems, surface freezing via a quantitized layer by layer growth of a smectic liquid crystal was found above the mesophase

Table 1 Model parameters of the XRR best fits (Fig. 5b) using eqn (4)

\begin{tabular}{|c|c|c|c|c|c|c|c|c|c|c|}
\hline$T\left({ }^{\circ} \mathrm{C}\right)$ & $L(\mathrm{~nm})$ & $\xi_{\mathrm{b}}^{a}(\mathrm{~nm})$ & $d(\mathrm{~nm})$ & $z_{0}(\mathrm{~nm})$ & $\sigma_{\mathrm{s}}(\mathrm{nm})$ & $S^{0 b}$ & $S^{-}$ & $B^{b}$ & $a_{2}$ & $\xi_{2}(\mathrm{~nm})$ \\
\hline 68 & $30.0 \pm 2.0$ & 4.78 & 3.73 & 2.28 & 0.18 & 1.71 & -98 & 126 & 0.15 & 26 \\
\hline 70 & $16.8 \pm 2.2$ & 4.73 & 3.73 & 2.29 & 0.17 & 1.64 & -152 & 12.6 & 0.15 & 18 \\
\hline 73 & $12.5 \pm 1.2$ & 4.64 & 3.73 & 2.24 & 0.10 & 1.62 & -189 & 6.50 & 0.12 & 19 \\
\hline 87 & $6.5 \pm 0.6$ & 4.21 & 3.70 & 2.14 & 0.18 & 1.58 & -294 & 2.90 & 0.15 & 9 \\
\hline 115 & $2.8 \pm 2.5$ & 3.38 & 3.56 & 1.89 & 0.25 & 1.55 & -503 & 0.19 & 0.05 & 20 \\
\hline
\end{tabular}

${ }^{a}$ Parameters were fixed to the interpolated bulk values extracted from SAXS. ${ }^{67}{ }^{b}$ Parameters were determined by continuity and differential continuity conditions. $\xi_{\mathrm{s}}$ was fixed at $2000 \mathrm{~nm}$. 
transition temperature. In contrast, continuous smectic order is characterized by a gradually decaying oscillating density profile. Notably, here the correlation length at the interface is larger than in the isotropic bulk. Several XRR studies, ${ }^{94,97-100}$ atomic-force microscopy ${ }^{101}$ and simulations ${ }^{102}$ show evidence for this phenomena. Surface induced continuous smectic order with prewetting is a mixture of the two cases discussed above. Here, a single smectic monolayer is wetting the surface. Below this first layer, similar to the continuous case an oscillating decaying profile is observed..$^{94}$

However, these different varieties of interface induced smectic order phenomena can be described within microscopic wetting theory ${ }^{103,104}$ based on smectic order parameter profiles. There, the film growth of undersaturated phases upon approaching two phase coexistence is studied, and phenomena like layering transitions or prewetting can occur. Depending on the intermolecular interaction potentials, phase transition entropies, and temperature one or the other of structures discussed above is realized.

The first category are liquid crystals that exhibit continuous or quasi-continuous bulk phase transitions, e.g., the commonly used 8-CB and 8-OCB with nematic-smectic transition. ${ }^{100}$ These transitions are characterized by a vanishing or negligible transition entropy $\Delta S .{ }^{87}$ Most of the previously studied LC systems fall in this category. In these systems, wetting theory predicts pinning of the smectic fluctuations at the surface of the nematic bulk. For continuous phase transitions, Ginzburg-Landau theory predicts that the correlation length $\xi_{\mathrm{s}}$ of the smectic fluctuations $v s$. reduced temperature $\tau$ scale with a power law

$$
\xi_{\mathrm{s}}(\tau)=\xi_{0} \tau^{-\nu}
$$

with the universal critical exponent $\nu$, which for the Ising model equals $1 / 2$ within mean field approximation and $\approx 0.63$ beyond. $^{97}$ As a result, the extension of the ordered surface structure close to the nematic-smectic transition diverges algebraically for $\tau \rightarrow 0$.

By contrast, at the isotropic-smectic transition of $\left[\mathrm{C}_{22} \mathrm{C}_{1} \mathrm{im}\right]^{+}\left[\mathrm{NTf}_{2}\right]^{-}$we find $\Delta S_{\mathrm{LC}}=2.5 \mathrm{~mol}^{-1} \mathrm{~K}^{-1}$, which signals a first-order bulk phase transition. From the observed logarithmic growth law for the layer thickness $L(\tau)$ one infers complete wetting and effectively short-ranged interactions. Hence, in $\left[\mathrm{C}_{22} \mathrm{C}_{1} \mathrm{im}\right]^{+}\left[\mathrm{NTf}_{2}\right]^{-}$the surface-induced smectic layer thickness $L$ reaches values that are substantially larger than its bulk correlation length $\xi_{\mathrm{b}}$.

Ultimately, the fundamental parameter connecting the system temperature with the surface structure is the prefactor $\Lambda$ in the growth law given by eqn (9c). According to theory, this parameter is linked to the bulk correlation length $\xi_{\mathrm{b}}$ in the isotropic phase. ${ }^{83,103,104}$ Indeed, we find a very good agreement of $\Lambda / d=1.2$ with the bulk value $\xi_{\mathrm{b}} / d=1.3$ determined by SAXS. ${ }^{67}$

A similar behavior is expected for other ILs, exhibiting smectic mesophases. However, in equilibrium surface induced smectic order will only be found for systems where $T_{1}>T_{\mathrm{m}}$. For example, by extrapolation a transition temperature $T_{\mathrm{LC}}=$ $-160{ }^{\circ} \mathrm{C}$ is predicted for the IL $\left[\mathrm{C}_{14} \mathrm{C}_{1} \mathrm{im}\right]^{+}\left[\mathrm{NTf}_{2}\right]^{-}$with shorter
$\mathrm{C}_{14}$ cation side chains. ${ }^{34}$ Assuming $\tau_{1}<0.3$, surface induced smectic order is only expected to be found below $-130{ }^{\circ} \mathrm{C}$. This temperature is about 170 Kelvin below its bulk melting point at $41{ }^{\circ} \mathrm{C}$.

However, for smaller anions such as $\left[\mathrm{BF}_{4}\right]$ and $\left[\mathrm{PF}_{6}\right]$ ILC transition temperatures $T_{\mathrm{LC}}$ strongly increase. For example, in $\left[\mathrm{C}_{14} \mathrm{C}_{1} \mathrm{im}\right]^{+}\left[\mathrm{PF}_{6}\right]^{-}$a value of $T_{\mathrm{LC}}-T_{\mathrm{m}}=5 \mathrm{~K}$ is found. ${ }^{34}$ Thus, surface induced smectic order might be also relevant for ILs composed of commonly used cations.

\section{Conclusions}

At the free $\left[\mathrm{C}_{22} \mathrm{C}_{1} \mathrm{im}\right]^{+}\left[\mathrm{NTf}_{2}\right]^{-}$surface, pronounced ordering was observed. Oscillatory surface profiles give rise to strong quasiBragg peaks in the XRR patterns. Quantitative analysis by fitting of model profiles shows that close to the melting point a smectic surface layer of thickness $L$ is wetting the isotropic bulk liquid. These findings are in conclusively agreement with MS-GS and MD simulations, showing smectic-like layering for some IL interfaces. ${ }^{43,105}$

Fig. 8 shows a schematic representation of the surface structures at $68{ }^{\circ} \mathrm{C}$ and $115{ }^{\circ} \mathrm{C}$. Notably, close to the melting point we find smectic layer thicknesses up to $30 \mathrm{~nm}$. This corresponds to an ordered surface structure, extending 8 times the smectic periodicity $d$ below the liquid surface. Therefore, unlike for other ILs such as $\left[\mathrm{C}_{18} \mathrm{C}_{1} \mathrm{im}\right]^{+}[\mathrm{FAP}]^{-}$, the oscillatory near surface structure persists far beyond the bulk correlation length of $\xi_{\mathrm{b}} / d=1.3$.

The ordered surface layer thickness $L v s$. temperature is quantitatively described by a logarithmic growth law. This dependency follows the prediction from a generic thermodynamic model for interface induced phase transitions. In agreement with theory, the pre-factor $\Lambda$ in the logarithmic growth law agrees with the bulk correlation length $\xi_{\mathrm{b}}$ of the isotropic liquid phase. Upon cooling, the smectic layer thickness $L / d$ in $\left[\mathrm{C}_{22} \mathrm{C}_{1} \mathrm{im}\right]^{+}\left[\mathrm{NTf}_{2}\right]^{-}$diverges at a temperature $T_{0}$. Interestingly,

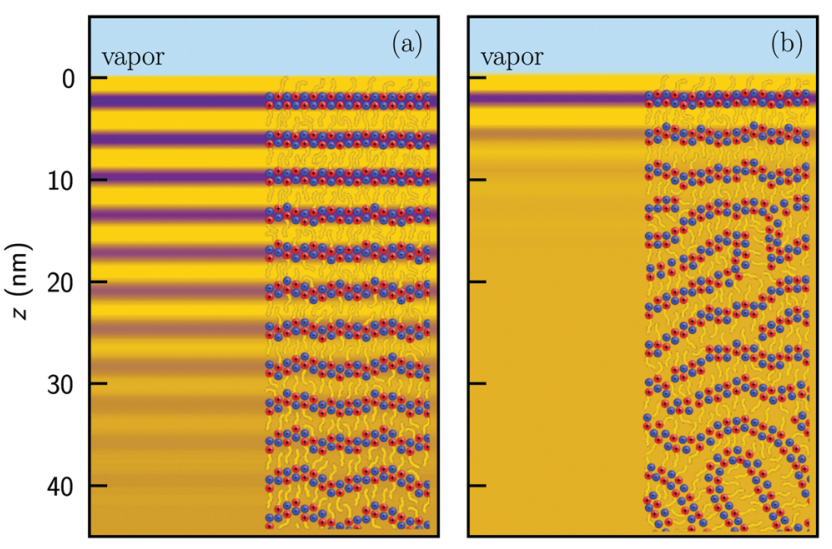

Fig. 8 Electron density profiles and schematic representation of the near surface structure at (a) $68{ }^{\circ} \mathrm{C}$ and (b) $115^{\circ} \mathrm{C}$. The size of anions (blue), imidazolium rings (red) and aliphatic side chains (yellow) are not to scale. Profiles are identical to Fig. 5b. The in-plane order (not shown) remains liquid-like for all temperatures. 
$T_{0}$ agrees well with the transition temperature $T_{\mathrm{LC}}$ of a metastable liquid crystalline smectic $\mathrm{SmA}_{2}$-mesophase formed from the supercooled isotropic liquid. This indicates that the observed layered surface structure in $\left[\mathrm{C}_{22} \mathrm{C}_{1} \mathrm{im}\right]^{+}\left[\mathrm{NTf}_{2}\right]^{-}$is governed by surface induced smectic order, i.e. fluctuations into the metastable $\mathrm{SmA}_{2}$-phase. On the other hand, we find an upper transition temperature of $T_{1}=157{ }^{\circ} \mathrm{C}$ for the ordered surface layer. Note that this behavior is very different from the power law scaling found for LCs with quasi-continuous nematic-smectic phase transitions. ${ }^{97,100}$ In contrast to other soft matter systems such as liquid crystals or alkanes, surface induced smectic ordering in the ionic liquid $\left[\mathrm{C}_{22} \mathrm{C}_{1} \mathrm{im}\right]^{+}\left[\mathrm{NTf}_{2}\right]^{-}$is relevant over a much larger temperatures range.

In bulk, smectic mesophases were found for a wide class of neat and mixed ILs. ${ }^{19}$ Based on our results, we therefore presume that similar surface structures are also formed in other ILs. From our previous bulk ${ }^{67}$ and surface studies, ${ }^{55}$ we anticipate that the tendency for surface induced smectic order is larger for smaller anions and longer aliphatic side chains. This tendency is supported by clear trends observed in a new volume based approach to predict the thermodynamical behavior of ILs and ILCs. ${ }^{34}$

The well ordered surface structures observed for $\left[\mathrm{C}_{22} \mathrm{C}_{1} \mathrm{im}\right]^{+}\left[\mathrm{NTf}_{2}\right]^{-}$over a surprisingly large temperature range might significantly reduce the diffusion of guest molecules across an IL/gas interface. Indeed, for $\left[\mathrm{C}_{16} \mathrm{C}_{1} \mathrm{im}\right]\left[\mathrm{NO}_{3}\right] \mathrm{MD}$ simulations show 5-fold smaller diffusion constants perpendicular to the layers of the smectic phase. ${ }^{106}$ Formation of such diffusion barriers for reactants and products, might adversely affect the performance of ILs in SILP processes. ${ }^{8}$ Further experiments on different ILs will be required to shed light on the complex interplay between the molecular structure of the anions and cations and the tendency for surface induced smectic order.

\section{Conflicts of interest}

There are no conflicts to declare.

\section{Acknowledgements}

Grazing incidence surface scattering and preliminary XRR data were obtained at ID10-EH1, ESRF The European Synchrotron, Grenoble, France. XRR experiments were conducted at the LISA instrument at beamline P08, Petra III, DESY, Hamburg, Germany funded by BMBF (project 05K10FK2 and 05K130FK2). We thank Gunnar Kircher (MPI-P) for $\left[\mathrm{C}_{22} \mathrm{C}_{1} \mathrm{im}\right]^{+}\left[\mathrm{NTf}_{2}\right]^{-}$synthesis, Xilin Wu (MPI-P) and Guoming Liu (Chin. Acad. Sci.) for assistance during the synchrotron experiments and Peter Reichert (MPI-P), Julia Haddad (Bar-Illan Univ.), and Hans-Jürgen Butt (MPI-P) for helpful discussions. J. M. and M. M. acknowledge the MAINZ Graduate School of Excellence, funded through the Excellence Initiative (DFG/GSC 266) and the German Israeli Foundation for scientific research and development (23062310.14/2011) for financial support. B. H. received a scholarship funded by the ESRF The European Synchrotron, Grenoble, France.
H. L. was supported by the China Scholarship Council. Open Access funding provided by the Max Planck Society.

\section{References}

1 L. Crowhurst, N. L. Lancaster, J. M. Pérez Arlandis and T. Welton, J. Am. Chem. Soc., 2004, 126, 11549-11555.

2 R. D. Rogers and K. R. Seddon, Science, 2003, 302, 792-793.

3 J. S. Wilkes, J. A. Levisky, R. A. Wilson and C. L. Hussey, Inorg. Chem., 1982, 21, 1263-1264.

$4 \mathrm{~W}$. Xu and C. A. Angell, Science, 2003, 302, 422-425.

5 A. Riisager, P. Wasserscheid, R. van Hal and R. Fehrmann, J. Catal., 2003, 219, 452-455.

6 R. Fehrmann, A. Riisager and M. Haumann, Supported ionic liquids: fundamentals and applications, John Wiley \& Sons, 2013.

7 H.-P. Steinrueck and P. Wasserscheid, Catal. Lett., 2015, 145, 380-397.

8 K. R. Lovelock, Phys. Chem. Chem. Phys., 2012, 14, 5071-5089.

9 A. Bradley, C. Hardacre, J. Holbrey, S. Johnston, S. McMath and M. Nieuwenhuyzen, Chem. Mater., 2002, 14, 629-635.

10 J. De Roche, C. M. Gordon, C. T. Imrie, M. D. Ingram, A. R. Kennedy, F. Lo Celso and A. Triolo, Chem. Mater., 2003, 15, 3089-3097.

11 A. Triolo, A. Mandanici, O. Russina, V. Rodriguez-Mora, M. Cutroni, C. Hardacre, M. Nieuwenhuyzen, H.-J. Bleif, L. Keller and M. A. Ramos, J. Phys. Chem. B, 2006, 110, 21357-21364.

12 A. Triolo, O. Russina, H.-J. Bleif and E. Di Cola, J. Phys. Chem. B, 2007, 111, 4641-4644.

13 K. Fujii, R. Kanzaki, T. Takamuku, Y. Kameda, S. Kohara, M. Kanakubo, M. Shibayama, S.-I. Ishiguro and Y. Umebayashi, J. Chem. Phys., 2011, 135, 244502.

14 C. S. Santos, N. S. Murthy, G. A. Baker and E. W. Castner Jr, J. Chem. Phys., 2011, 134, 121101.

15 H. K. Kashyap, J. J. Hettige, H. V. Annapureddy and C. J. Margulis, Chem. Commun., 2012, 48, 5103-5105.

16 H. K. Kashyap, C. S. Santos, H. V. Annapureddy, N. S. Murthy, C. J. Margulis and E. W. Castner Jr, Faraday Discuss., 2012, 154, 133-143.

17 R. Caminiti and L. Gontrani, The structure of ionic liquids, Springer, 2014, vol. 193.

18 K. Fujii, S. Kohara and Y. Umebayashi, Phys. Chem. Chem. Phys., 2015, 17, 17838-17843.

19 F. Nemoto, M. Kofu and O. Yamamuro, J. Phys. Chem. B, 2015, 119, 5028-5034.

20 C. Hardacre, J. D. Holbrey, C. L. Mullan, T. G. Youngs and D. T. Bowron, J. Chem. Phys., 2010, 133, 074510.

21 S. Shigeto and H.-o. Hamaguchi, Chem. Phys. Lett., 2006, 427, 329-332.

22 C. Margulis, Mol. Phys., 2004, 102, 829-838.

23 A. A. Pádua, M. F. Costa Gomes and J. N. Canongia Lopes, Acc. Chem. Res., 2007, 40, 1087-1096.

24 J. N. Canongia Lopes and A. A. Pádua, J. Phys. Chem. B, 2006, 110, 3330-3335. 
25 H. V. Annapureddy, H. K. Kashyap, P. M. De Biase and C. J. Margulis, J. Phys. Chem. B, 2010, 114, 16838-16846.

26 K. Shimizu, M. F. C. Gomes, A. A. Pádua, L. P. Rebelo and J. N. C. Lopes, THEOCHEM, 2010, 946, 70-76.

27 J. J. Hettige, H. K. Kashyap, H. V. Annapureddy and C. J. Margulis, J. Phys. Chem. Lett., 2012, 4, 105-110.

28 K. Shimizu, C. E. Bernardes and J. N. Canongia Lopes, J. Phys. Chem. B, 2014, 118, 567-576.

29 J. C. Araque, J. J. Hettige and C. J. Margulis, J. Phys. Chem. B, 2015, 119, 12727-12740.

30 C. J. Bowlas, D. W. Bruce and K. R. Seddon, Chem. Commun., 1996, 1625-1626.

31 C. M. Gordon, J. D. Holbrey, A. R. Kennedy and K. R. Seddon, J. Mater. Chem., 1998, 8, 2627-2636.

32 J. D. Holbrey and K. R. Seddon, J. Chem. Soc., Dalton Trans., 1999, 2133-2140.

33 C. Hardacre, J. D. Holbrey, P. B. McCormac, S. J. McMath, M. Nieuwenhuyzen and K. R. Seddon, J. Mater. Chem., 2001, 11, 346-350.

34 Y. V. Nelyubina, A. S. Shaplov, E. I. Lozinskaya, M. I. Buzin and Y. S. Vygodskii, J. Am. Chem. Soc., 2016, 138, 10076-10079.

35 Y. Ji, R. Shi, Y. Wang and G. Saielli, J. Phys. Chem. B, 2013, 117, 1104-1109.

36 Y. Wang and G. A. Voth, J. Am. Chem. Soc., 2005, 127, 12192-12193.

37 Y. Wang and G. A. Voth, J. Phys. Chem. B, 2006, 110, 18601-18608.

38 G. Saielli, Soft Matter, 2012, 8, 10279-10287.

39 G. Saielli, A. Bagno and Y. Wang, J. Phys. Chem. B, 2015, 119, 3829-3836.

40 G. Saielli and Y. Wang, J. Phys. Chem. B, 2016, 120, 9152-9160.

41 R. Lynden-Bell and M. Del Popolo, Phys. Chem. Chem. Phys., 2006, 8, 949-954.

42 R. M. Lynden-Bell, M. G. Del Pópolo, T. G. Youngs, J. Kohanoff, C. G. Hanke, J. B. Harper and C. C. Pinilla, Acc. Chem. Res., 2007, 40, 1138-1145.

43 W. D. Amith, J. J. Hettige, E. W. Castner and C. J. Margulis, J. Phys. Chem. Lett., 2016, 3785-3790.

44 C. Kolbeck, T. Cremer, K. Lovelock, N. Paape, P. Schulz, P. Wasserscheid, F. Maier and H.-P. Steinruck, J. Phys. Chem. B, 2009, 113, 8682-8688.

45 F. Maier, T. Cremer, C. Kolbeck, K. Lovelock, N. Paape, P. Schulz, P. Wasserscheid and H.-P. Steinrück, Phys. Chem. Chem. Phys., 2010, 12, 1905-1915.

46 V. Lockett, R. Sedev, S. Harmer, J. Ralston, M. Horne and T. Rodopoulos, Phys. Chem. Chem. Phys., 2010, 12, 13816-13827.

47 K. R. Lovelock, I. J. Villar-Garcia, F. Maier, H.-P. SteinruİĹck and P. Licence, Chem. Rev., 2010, 110, 5158-5190.

48 C. Kolbeck, A. Deyko, T. Matsuda, F. T. Kohler, P. Wasserscheid, F. Maier and H.-P. Steinrück, ChemPhysChem, 2013, 14, 3726-3730.

49 C. Kolbeck, I. Niedermaier, A. Deyko, K. R. Lovelock, N. Taccardi, W. Wei, P. Wasserscheid, F. Maier and H.-P. Steinrück, Chem. - Eur. J., 2014, 20, 3954-3965.
50 S. Rivera-Rubero and S. Baldelli, J. Phys. Chem. B, 2006, 110, 4756-4765.

51 C. S. Santos and S. Baldelli, J. Phys. Chem. B, 2009, 113, 923-933.

52 E. Sloutskin, B. M. Ocko, L. Tamam, I. Kuzmenko, T. Gog and M. Deutsch, J. Am. Chem. Soc., 2005, 127, 7796-7804.

53 N. Nishi, Y. Yasui, T. Uruga, H. Tanida, T. Yamada, S.-I. Nakayama, H. Matsuoka and T. Kakiuchi, J. Chem. Phys., 2010, 132, 164705.

54 N. Nishi, T. Uruga, H. Tanida and T. Kakiuchi, Langmuir, 2011, 27, 7531-7536.

55 M. Mezger, B. M. Ocko, H. Reichert and M. Deutsch, Proc. Natl. Acad. Sci. U. S. A., 2013, 110, 3733-3737.

56 M. Mezger, H. Schröder, H. Reichert, S. Schramm, J. S. Okasinski, S. Schöder, V. Honkimäki, M. Deutsch, B. M. Ocko and J. Ralston, Science, 2008, 322, 424-428.

57 M. Mezger, S. Schramm, H. Schröder, H. Reichert, M. Deutsch, E. J. De Souza, J. S. Okasinski, B. M. Ocko, V. Honkimäki and H. Dosch, J. Chem. Phys., 2009, 131, 094701.

58 Z. Brkljača, M. Klimczak, Z. Miličević, M. Weisser, N. Taccardi, P. Wasserscheid, D. M. Smith, A. Magerl and A.-S. Smith, J. Phys. Chem. Lett., 2015, 6, 549-555.

59 T. A. Petach, A. Mehta, R. Marks, B. Johnson, M. F. Toney and D. Goldhaber-Gordon, ACS Nano, 2016, 10, 4565-4569.

60 Y. Jeon, D. Vaknin, W. Bu, J. Sung, Y. Ouchi, W. Sung and D. Kim, Phys. Rev. Lett., 2012, 108, 055502.

61 L. A. Jurado, H. Kim, A. Arcifa, A. Rossi, C. Leal, N. D. Spencer and R. M. Espinosa-Marzal, Phys. Chem. Chem. Phys., 2015, 17, 13613-13624.

62 R. S. Anaredy and S. K. Shaw, Langmuir, 2016, 5147-5154.

63 T. Li, F. Xu and W. Shi, Chem. Phys. Lett., 2015, 628, 9-15.

64 E. F. G. Herington, Zone melting of organic compounds, Wiley, 1963.

65 W. R. Wilcox, R. Friedenberg and N. Back, Chem. Rev., 1964, 64, 187-220.

66 A. R. Choudhury, N. Winterton, A. Steiner, A. I. Cooper and K. A. Johnson, J. Am. Chem. Soc., 2005, 127, 16792-16793.

67 H. Weiss, J. Mars, H. Li, G. Kircher, O. Ivanova, A. Feoktystov, O. Soltwedel, M. Bier and M. Mezger, J. Phys. Chem. B, 2017, 121, 620-629.

68 B. M. Murphy, M. Greve, B. Runge, C. T. Koops, A. Elsen, J. Stettner, O. H. Seeck and O. M. Magnussen, J. Synchrotron Radiat., 2014, 21, 45-56.

69 B. L. Henke, E. M. Gullikson and J. C. Davis, At. Data Nucl. Data Tables, 1993, 54, 181-342.

70 C. T. Chantler, J. Phys. Chem. Ref. Data, 1995, 24, 71-643.

71 C. T. Chantler, J. Phys. Chem. Ref. Data, 2000, 29, 597-1056.

72 M. Tolan, X-ray scattering from soft-matter thin films: materials science and basic research, Springer Berlin, 1999.

$73 \mathrm{~J}$. Als-Nielsen and D. McMorrow, Elements of modern X-ray physics, Wiley, 2011.

74 K.-M. Zimmermann, M. Tolan, R. Weber, J. Stettner, A. Doerr and W. Press, Phys. Rev. B: Condens. Matter Mater. Phys., 2000, 62, 10377. 
75 T. Hohage, K. Giewekemeyer and T. Salditt, Phys. Rev. E: Stat., Nonlinear, Soft Matter Phys., 2008, 77, 051604.

76 L. Nevot and P. Croce, Rev. Phys. Appl., 1980, 15, 761-779.

77 P. de Gennes and J. Prost, The physics of liquid crystals, Oxford, 1998.

78 L. G. Parratt, Phys. Rev., 1954, 95, 359.

79 L. Ingber, Math. Comput. Modell., 1993, 18, 29-57.

80 A. Braslau, P. S. Pershan, G. Swislow, B. Ocko and J. Als-Nielsen, Phys. Rev. A: At., Mol., Opt. Phys., 1988, 38, 2457.

81 M. Sanyal, S. Sinha, K. Huang and B. Ocko, Phys. Rev. Lett., 1991, 66, 628.

82 C. Kolbeck, J. Lehmann, K. Lovelock, T. Cremer, N. Paape, P. Wasserscheid, A. Froba, F. Maier and H.-P. Steinruck, J. Phys. Chem. B, 2010, 114, 17025-17036.

83 R. Lipowsky, Phys. Rev. Lett., 1982, 49, 1575.

84 J. F. Van Der Veen, Surf. Sci., 1999, 433, 1-11.

85 Y. Yang, M. Asta and B. B. Laird, Phys. Rev. Lett., 2013, 110, 096102.

86 B. Ocko, X. Wu, E. Sirota, S. Sinha, O. Gang and M. Deutsch, Phys. Rev. E: Stat. Phys., Plasmas, Fluids, Relat. Interdiscip. Top., 1997, 55, 3164.

87 W. E. Acree Jr and J. S. Chickos, J. Phys. Chem. Ref. Data, 2006, 35, 1051-1330.

88 I. Dierking, Textures of liquid crystals, John Wiley \& Sons, 2003.

89 P. S. Pershan and M. Schlossman, Liquid Surfaces and Interfaces: Synchrotron X-ray Methods, Cambridge University Press, 2012.

90 J. Als-Nielsen, D. Jacquemain, K. Kjaer, F. Leveiller, M. Lahav and L. Leiserowitz, Phys. Rep., 1994, 246, 251-313.
91 M. Mezger, R. Roth, H. Schröder, P. Reichert, D. Pontoni and H. Reichert, J. Chem. Phys., 2015, 142, 164707.

92 B. Ocko, A. Braslau, P. S. Pershan, J. Als-Nielsen and M. Deutsch, Phys. Rev. Lett., 1986, 57, 94.

93 B. Ocko, Phys. Rev. Lett., 1990, 64, 2160.

94 R. Lucht, P. Marczuk, C. Bahr and G. Findenegg, Phys. Rev. E: Stat., Nonlinear, Soft Matter Phys., 2001, 63, 041704.

95 G. S. Iannacchione, J. T. Mang, S. Kumar and D. Finotello, Phys. Rev. Lett., 1994, 73, 2708.

96 J. V. Selinger and D. R. Nelson, Phys. Rev. A: At., Mol., Opt. Phys., 1988, 37, 1736.

97 J. Als-Nielsen, F. Christensen and P. S. Pershan, Phys. Rev. Lett., 1982, 48, 1107.

98 P. S. Pershan and J. Als-Nielsen, Phys. Rev. Lett., 1984, 52, 759.

99 P. S. Pershan, A. Braslau, A. Weiss and J. Als-Nielsen, Phys. Rev. A: At., Mol., Opt. Phys., 1987, 35, 4800.

100 M. Fukuto, O. Gang, K. J. Alvine, B. M. Ocko and P. S. Pershan, Phys. Rev. E: Stat., Nonlinear, Soft Matter Phys., 2008, 77, 031607.

101 K. Kočevar and I. Muševič, Phys. Rev. E: Stat., Nonlinear, Soft Matter Phys., 2002, 65, 021703.

102 L. Mederos and D. Sullivan, Phys. Rev. A: At., Mol., Opt. Phys., 1992, 46, 7700.

103 S. Dietrich, Phase Transitions and Critical Phenomena, 1988, pp. 1-218.

104 M. Schick, Liquids at Interfaces, Les Houches Session XLVIII, 1988, pp. 415-497.

105 W. Jiang, Y. Wang, T. Yan and G. A. Voth, J. Phys. Chem. C, 2008, 112, 1132-1139.

106 G. Saielli, G. A. Voth and Y. Wang, Soft Matter, 2013, 9, 5716-5725. 